American Journal of Environmental Sciences 7 (4): 331-337, 2011

ISSN 1553-345X

(C) 2011 Science Publications

\title{
Trends in Maximum Daily Rainfall in Marginal Desert Environment: Signs of Climate Change
}

\author{
${ }^{1}$ Khaldoun A. Al-Qudah and ${ }^{2}$ Abdullah A. Smadi \\ ${ }^{1}$ UNESCO Chair for Desert Studies, \\ Yarmouk University, Irbid 21163, Jordan \\ ${ }^{2}$ Department of Statistics, Faculty of Science, \\ Yarmouk University, Irbid 21163, Jordan
}

\begin{abstract}
Problem statement: Change in intense precipitation has been used as an indicator for anticipated climate change. The trend in maximum daily rainfall in 10 rainfall stations distributed in the north and north east of Jordan has been investigated. Based on mean annual rainfall and geographic location, rainfall stations were divided into subhumid, semi-arid and arid stations. Approach: The regression approach T-test and Mann-Kendall test were used to investigate significant trends in maximum daily rainfall. Logistic regression model used to test the trends in the frequency of heavy rainfall. Based on p-vales, significant trends were determined. Results: The results show that pronounced significant decreasing trend is observed in three out of four semi-arid stations used in this study. In arid stations, only one station out of three show significant increasing trend. However, none of the three subhumid stations used in the study show any significant trend. Logistic regression test for readings above 90th percentile among the maximum daily rainfall shows significant downward trend only in the semi-arid stations. Conclusion: The results of this study confirm that semi-arid zone is more vulnerable to climate change. Serious actions to mitigate and adapt to climate changes should be given a priority in the semi-arid zone. Redistribution of daily rainfall intensity will have a significant impact on water resources management.
\end{abstract}

Key words: Maximum daily rainfall, climate change, trend analysis, semi-arid, global warming, Generalized Linear Model (GLM), Odds Ratio (OR), semi-arid zone, regression model

\section{INTRODUCTION}

Change in intense precipitation has been used as an indicator for anticipated climate change. Any change in precipitation behavior will significantly impact both natural environment and human life. There is an increasing evidence that human-induced climate change, "global warming", is changing the behavior of precipitation, especially, the extremes (Easterling et al., 2000; 2011; Trenberth, 2008; Black, 2009; Trenberth, 2011; Karl and Knight, 1995). Arid and semi arid regions, such as Jordan, mainly depend on rainfall as the main source of water supply. Therefore, changes in rainfall behavior as results of climate change will influence water supply sources and other water related management issues. One of the major concerns with a potential change in climate is that an increase in extreme events i.e., mainly floods and droughts will occur (Trenberth, 2005).
Most countries that experienced a significant increase or decrease in monthly or seasonal precipitation also experienced a disproportionate change in the amount of precipitation falling during the heavy and extreme precipitation events (Easterling et al., 2011; Groisman et al., 2005). Patterns of where it rains also have been observed to change, with dry areas becoming drier (generally throughout the subtropics) and wet areas becoming wetter especially in the mid to high latitudes (Trenberth, 2011).

In east Mediterranean region, general negative trends in all precipitations indices has been reported (Kadioglu et al., 1999; Kostopoulou and Jones, 2005; Oikonomon et al. (2008)). For example, Oikonomou et al. (2008) studied future changes in the occurrence of extreme precipitation events in eastern Mediterranean. They found a general tendency for drier eastern Mediterranean with a reduction in rainfall intensity.

Corresponding Author: Khaldoun A. Al-Qudah, UNESCO Chair for Desert Studies, Yarmouk University, Irbid 21163, Jordan Tel: +962-2-7211111 ext 2921 Fax: +962-2-7211117 
In Jordan, most studies on precipitation were focused on trends in mean daily, monthly and annual. In general, no statistically significant trend has been found (Freiwan and Kadioglu, 2008a; 2008b); Ghanem, 2011). Decline in the total rainfall and number of rain days in the second half of the past century has been reported in Jordan (Smadi and Zghoul, 2006). Trends in maximum and intense precipitation in Jordan are not understood yet, however, it may draw attention to any possible climate change in the region especially as it is more sensitive index to climate change than any other climatic indices. Therefore, this study comes to highlight the trends in maximum daily rainfall as an indicator for any possible climate change in a transition climate zone in north and north east of Jordan.

Study area: Jordan is located in the southeastern edge of the Mediterranean and to the northwestern corner of the Arabian Peninsula Fig. 1. Therefore and from climatic point of view, it represents a transitional environment between Mediterranean subhumid climate in the northwestern parts and the semi arid to arid climate in most of the country.

The study area represents the northern parts of the eastern hills and northeastern desert plains (Fig. 1).

The rainy season in Jordan starts from October to May of the next year with $80 \%$ of rainfall occurs during the winter months from December to February. Mean annual rainfall ranges from $50-600 \mathrm{~mm}$ with more than $80 \%$ of country receives less than $150 \mathrm{~mm}$ year $^{-1}$. Precipitation is influenced mainly by depression lows crossing through east Mediterranean mainly during winter months; however, instability conditions influenced by the effect of the Red Sea Trough cause precipitation especially in the fall and spring time (Al-Qudah, 2011).

\section{MATERIALS AND METHODS}

There are different authorities that collect rainfall and other weather elements in Jordan such as Ministry of Water and Irrigation, Ministry of Agriculture and Jordan Meteorological Department (JMD). However, JMD is the only agency that has well-equipped, welltrained staff to monitor and collect weather data. While there are many rainfall stations in the study area, only 10 stations which belong to JMD were chosen. The data are of good-quality, because of good monitoring and maintain on these stations. The stations profiles are shown in Table 1 and for stations location Fig. 1. The very few missing data within the selected stations were treated with suitable statistical and hydrological approach.
The reengages used in this study are distributed in the northeastern hills and the northeastern desert plains of Jordan. From a climatological point of view, the stations of Irbid (IRB), Ras Muneef (RAS) and Jordan University (JOU) are representing subhumid climate zone with mean annual rainfall ranges from 400600mm. Amman Airport (AMM), Zarqa (ZAR), Mafraq (MAF) and Queen Alia Airport (QAI) stations are representing semiarid climate zone with mean annual rainfall ranges from $100-300 \mathrm{~mm}$. While stations of Azraq (AZR), Safawi (H5) and Ruwashid (H4) are representing arid climate zone with mean annual rainfall of less than $100 \mathrm{~mm}$.

The original data consists of daily rainfall data covering different time periods (Table 1). However, for a more accurate analysis the data are transformed into rainyyears scale. It is assumed that the rainy year starts by the first of October and ends by the $31^{\text {st }}$ of May next year.

In this study, we use time series analysis to investigate the trends in mean annual rainfall sum, mean maximum annual daily rainfall and trend in events with rainfall above 90th percentile among the maximum. We use three approaches to test the trends, namely the Trtest via regression analysis and the Mann-Kendall test and logistic regression model. The first two approaches are used to study the trend in rainfall sum and maximum daily rainfall as those variables are quantitative. The later is used to study the trend in rainfall above 90th percentile among the maximum as this variable is a binary (indicator) variable.

Linear trend model: Given a time series $X_{1}, X_{2}, \ldots, X_{n}$ then the linear trend model is given by:

$$
X_{t}=\beta_{0}+\beta_{1} t+\varepsilon_{t}, t=1 \ldots n
$$

where, $\beta_{0}$ and $\beta_{1}$ are the intercept and slope parameters, respectively and $\left\{\varepsilon_{\mathrm{t}}\right\}$ are random errors assumed independent and normally distributed with mean zero and constant variance $\sigma_{\varepsilon}^{2}$. This model is usually fitted using ordinary simple linear regression approach. The standard statistical packages including Excel can be used to obtain such fitted equation. Usually, such packages provide ANOVA table of regression and $\tilde{\mathrm{p} \text {-values for }}$ both the intercept and slope parameters. The $\tilde{p}$-value of the slope is usually used to carry out a two-sided test for significant trend in the time series. This test is a parametric statistical test that is based on the $t$ distribution and requires several assumptions as mentioned above. This test is also sensitive for the presence of outliers. 
Am. J. Environ. Sci., 7 (4): 331-337, 2011

Table 1: Some descriptive measures for the rainfall in the stations used in the study

\begin{tabular}{|c|c|c|c|c|c|c|c|c|c|c|}
\hline \multirow[b]{2}{*}{ Region } & \multirow[b]{2}{*}{ Station } & \multirow[b]{2}{*}{ Duration } & \multirow[b]{2}{*}{$\begin{array}{l}\text { Length } \\
\text { (Years) }\end{array}$} & \multicolumn{2}{|c|}{ Coordinates } & \multirow[b]{2}{*}{$\begin{array}{l}\text { Elevation } \\
\mathrm{m} \text { asl** }\end{array}$} & \multirow[b]{2}{*}{$\mathrm{MAD}(\mathrm{mm})$} & \multirow[b]{2}{*}{ MAS(mm) } & \multirow[b]{2}{*}{$\operatorname{MAD}(\operatorname{Max})(\mathrm{mm})$} & \multirow[b]{2}{*}{ CV(Max) } \\
\hline & & & & Lat. & Long. & & & & & \\
\hline \multirow[t]{3}{*}{ Sub-humid } & RAS & 1976-2009 & 34 & $32 \circ 22^{\prime}$ & $35^{\circ} 45^{\prime}$ & 1150 & 9.46 & 581.72 & 55.89 & 26.74 \\
\hline & JOU & $1970-2008$ & 39 & $32{ }^{\circ} 01^{\prime}$ & $35^{\circ} 53^{\prime}$ & 980 & 10.42 & 502.19 & 64.72 & 33.24 \\
\hline & IRB & 1970-2009 & 40 & $32^{\circ} 33^{\prime}$ & $35^{\circ} 51^{\prime}$ & 616 & 7.90 & 461.79 & 48.27 & 27.25 \\
\hline \multirow[t]{4}{*}{ Semi-arid } & MAF & 1941-2009 & 69 & $32 \circ 22^{\prime}$ & $36^{\circ} 15^{\prime}$ & 686 & 4.72 & 144.68 & 21.87 & 51.98 \\
\hline & QAI & 1970-2009 & 40 & $31 \circ 43^{\prime}$ & $35^{\circ} 59^{\prime}$ & 715 & 4.16 & 158.57 & 25.22 & 40.18 \\
\hline & AMM & 1923-2009 & 87 & $31 \circ 59^{\prime}$ & $35^{\circ} 59^{\prime}$ & 766 & 5.59 & 267.53 & 39.76 & 35.87 \\
\hline & ZAR & $1970-2009$ & 40 & $32 \circ 05^{\prime}$ & $36^{\circ} 07^{\prime}$ & 555 & 3.82 & 130.69 & 20.07 & 40.82 \\
\hline \multirow[t]{3}{*}{ Arid } & AZR & 1968-2009 & 42 & $31 \circ 50^{\prime}$ & $36^{\circ} 49^{\prime}$ & 521 & 3.16 & 55.48 & 14.81 & 64.60 \\
\hline & $\mathrm{H} 4$ & $1942-2009$ & 68 & $32 \circ 30^{\prime}$ & $38^{\circ} 12^{\prime}$ & 683 & 3.22 & 72.98 & 16.43 & 58.46 \\
\hline & H5 & $1942-2009$ & 68 & $32 \circ 12^{\prime}$ & $37 \circ 08^{\prime}$ & 672 & 3.22 & 68.08 & 15.60 & 59.73 \\
\hline
\end{tabular}

*m asl: meters above sea level; MAD: Mean Annual Daily rainfall; MAD (MAX): mean annual daily maximum rainfall MAS: Mean Annual Sum; CV: Coefficient of Variance of MAD (MAX)

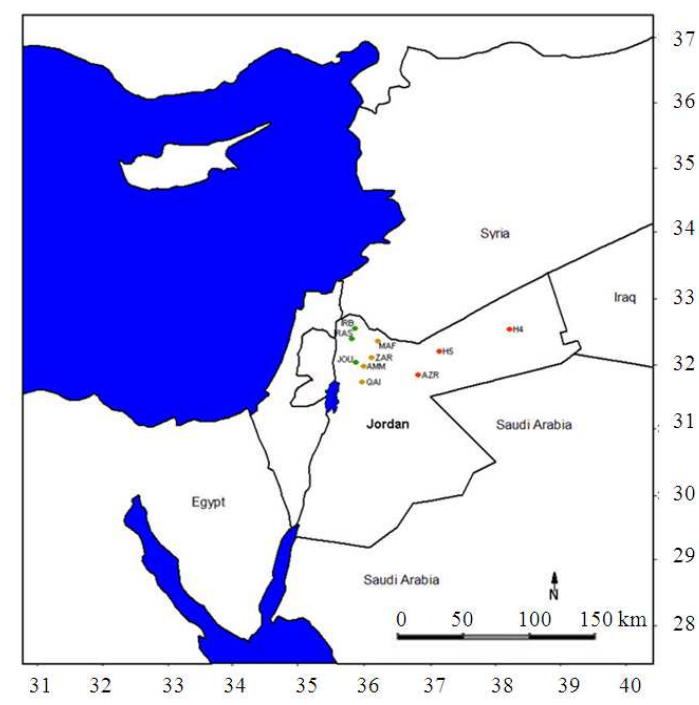

Fig. 1: Location map of Jordan and rainfall station in the study

Mann-Kendall trend test: The Mann-Kendall (MK) test is a very popular test of trend especially in climatology and related fields. It is a non-parametric test which only assumes that the observations are independent. Given a time series $X_{1}, X_{2}, \ldots, X_{n}$ then the test is carried out as follows.

Let $S$ be the number of occurrences of $X_{i}<X_{j}$ for $i$ $<\mathrm{j}$ in the given time series. Then the statistic:

$$
\mathrm{u}=\left(\frac{4 \mathrm{~S}}{\mathrm{n}(\mathrm{n}-1)}\right)-1
$$

Is asymptotically normally distributed with mean zero and standard deviation:

$$
\sigma(\mathrm{u})=\sqrt{\frac{2 \mathrm{n}(\mathrm{n}+5)}{9 \mathrm{n}(\mathrm{n}-1)}}
$$

Thus, the test-statistic of the MK-test is $Z^{*}=u / \sigma(u)$ which has asymptotically a standard normal distribution. Therefore, a two-sided test for the presence of trend in a time series is considered significant at significance level $\alpha$ if $\left|Z^{*}\right| Z_{\alpha / 2}$. We can also apply this test for investigating a one-sided trend, i.e. upward or downward. For instance, for testing the presence of an upward trend in a time series the test is considered significant if $Z^{*}>Z_{\alpha}$.

As the MK-test it is based on the ranks of data it is more robust for the presence of outliers than other tests including the T-test. If the assumptions of the T-test are satisfied and no outliers are detected in data, then the Ttest is usually more powerful than the MK-test. Besides, if the MK-test indicates a significant trend then usually the linear trend model above is fitted to obtain an estimate of this trend. Onoz and Bayazit (2003) made a comparison between the MK-test and the T-test through simulation and investigated the ability of detecting trends in stream-flow data in various regions of Turkey.

Logistic regression model: The logistic regression model is a Generalized Linear Model (GLM) used for modelling the relationship between a binary response variable $\mathrm{Y}$ with probability of success $\pi$ against the predictor X. Assuming that the random component is binomial, this model is written as:

$\log \operatorname{it}(\pi)=\ln \left(\frac{\pi}{1-\pi}\right)=\alpha+\beta x$.

This model is very important in modelling binary response variables, especially in medicine for modelling the risk of having some disease $(\pi)$ against some factor X. In this article, this model will be used to study the relationship between the chances (probability) that the maximum daily rainfall in any year $t$ falls above the 90th percentile of annual maximums versus the year 
t. A fitted model with negative (significant) slope indicates that the chances of maximum daily rainfall being above the 90th percentile decrease along with time. The slope parameter, $\beta$, is better interpreted through $\mathrm{e}^{\beta}$ which equals the Odds Ratio (OR). For instance, an OR value greater (smaller) than one indicates that the risk probability, $\pi$, increases (decreases) as $\mathrm{X}$ is increased. For more details on logistic regression see Agresti (1996).

\section{RESULTS}

Mean daily, mean annual and mean (maximum) daily rainfall and the coefficient of variation $(\mathrm{CV})$ for the rainfall stations in the study are presented in Table 1. The subhumid stations (IRB, RAS and JOU) have mean daily rainfall ranges $7.9-10.4 \mathrm{~mm}$; mean annual rainfall ranges $461-581 \mathrm{~mm}$; mean daily maximum ranges 48.3-64.7mm and $\mathrm{CV}$ ranges 26.7-33.2. The semi arid stations (MAF, QAI, AMM and ZAR) have mean daily rainfall ranges 3.8-5.6 $\mathrm{mm}$; mean annual ranges from $130-267 \mathrm{~mm}$; mean maximum daily $20-$ $40 \mathrm{~mm}$ and $\mathrm{CV}$ ranges 35.9-52. While the stations (AZR, H5and H4) are the arid zone stations with mean daily rainfall of $3.2 \mathrm{~mm}$; mean annual ranges $55-73 \mathrm{~mm}$; mean maximum of 14.8-16.3 $\mathrm{mm}$ and $\mathrm{CV}$ ranges 58-64. The CV, which is a unitless measure of variability, is reported here because of the difference among rainfall data in various stations. The CV values in maximum daily rainfalls show the largest (smallest) variability in arid (sub-humid) stations.

For the mean annual trend, only two stations show statistically significant decreasing trend using T-test. MAF station (semi arid station) shows decreasing trend with p-value of 0.058 and AZR (arid station) also shows decreasing trend with p-value of 0.031 . On the contrary, none of the subhumid stations show any significant trend.
Maximum daily rainfall trends: The mean daily maximum rainfall for the stations is presented in Table 1. Trends in maximum daily rainfall are presented in Table 2. Fitted linear trend using T-test and MK test are presented in Table 2. Subhumid stations show no significant trend in maximum daily rainfall as it shown from the p-values as tested by both T-test and MK. However, RAS and JOU show positive slope while IRB shows a slight negative slope Table 2. In semi-arid stations, all stations show downward trend in maximum daily rainfall (Fig. 2) among which, three out of four were statistically significant. The significance is confirmed by both the p-values of MK test (MAF; 0.0074, QAI; 0.0999 and AMM; 0.0063) and the pvalues of T-test (MFR; 0.015, QAI; 0.054 and AMM; 0.004).

In arid stations, which are represented by AZR, H5 and $\mathrm{H} 4$, only $\mathrm{H} 4$ shows statistically significant but increasing trend in mean maximum daily rainfall (Fig. 3) with $\mathrm{p}$-value $=0.003$ using $\mathrm{MK}$ test and $\mathrm{p}$-value $=$ 0.022 using T-test (Table 2).

Heavy rainfall (rainfall events above $90^{\text {th }}$ percentiles): Heavy annual daily rainfall events which are defined in this study to be events with mean annual daily maximum intensity above 90th percentiles among the maximum were also tested in this study. The trend in the mean daily maximum events above the 90th percentile was tested using the logistic regression model (Table 3). Only in semi arid stations significant downward trend with OR values less than one is observed with p-values (MAF; 0.09, QAI; 0.024 and AMM; 0.018). For other stations, insignificant upward trend is observed for JOU and H4 stations (Table 3). The frequency of the events above $90^{\text {th }}$ percentile within the maximum daily is decreasing with time in semi-arid stations (Fig. 4).

Table 2: Tests of significant trend for mean annual sum rainfall MAS, and mean annual daily maximum rainfall MAD (Max) using T-test and

\begin{tabular}{|c|c|c|c|c|c|}
\hline \multirow[b]{2}{*}{ Region } & \multirow[b]{2}{*}{ Station } & \multicolumn{2}{|l|}{ MA sum } & \multicolumn{2}{|l|}{ MAD (max) } \\
\hline & & Trend (P-value $)^{\mathrm{a}}$ & Trend (P-value $)^{\mathrm{a}}$ & Downward $^{\mathrm{b}}$ & Upward $^{\mathrm{b}}$ \\
\hline \multirow[t]{3}{*}{ Sub-Humid } & RAS & $1.39(0.667)$ & $0.235(0.376)$ & 0.8962 & 0.1038 \\
\hline & JOU & $0.07(0.978)$ & $0.208(0.504)$ & 0.6004 & 0.3996 \\
\hline & IRB & $-1.35(0.513)$ & $-0.046(0.800)$ & 0.4954 & 0.5047 \\
\hline \multirow[t]{4}{*}{ Semi-arid } & MAF & $-0.760\left(0.058^{*}\right)$ & $-0.170\left(0.015^{* *}\right)$ & $0.0074 * * *$ & 0.9926 \\
\hline & QAI & $-1.10(0.150)$ & $-0.266(0.054 *)$ & $0.0999 *$ & 0.9001 \\
\hline & AMM & $-0.488(0.208)$ & $-0.170(0.004 * * *)$ & $0.0063 * * *$ & 0.9937 \\
\hline & ZAR & $-0.397(0.599)$ & $-0.065(0.569)$ & 0.3417 & 0.6583 \\
\hline \multirow[t]{3}{*}{ Arid } & AZR & $-0.911\left(0.031^{* *}\right)$ & $-0.172(0.176)$ & $0.0905^{*}$ & 0.9095 \\
\hline & $\mathrm{H} 4$ & $-0.110(0.588)$ & $0.135\left(0.022^{* *}\right)$ & 0.9969 & 0.0030 *** \\
\hline & H5 & $-0.198(0.413)$ & $0.017(0.771)$ & 0.6166 & 0.3834 \\
\hline
\end{tabular}

a: P-values based on T-test. b: P-values based on MK-test. *: Significant at $\alpha \leq 0.1$; **: Significant at $\alpha \leq 0.05$; ***: Significant at $\alpha \leq 0.01$ 
Am. J. Environ. Sci., 7 (4): 331-337, 2011

Table 3: Logistic Regression of readings above the 90th percentile of MAD (max)

\begin{tabular}{|c|c|c|c|c|c|}
\hline Region & Station & $\mathrm{P}_{90}$ & Fitted Model & Est. OR & P-Value \\
\hline \multirow[t]{3}{*}{ Sub-Humid } & RAS & 78.4 & $\operatorname{Logit}(\hat{\pi})=-0.976-0.149 \mathrm{yr}$ & 0.86 & 0.111 \\
\hline & $\mathrm{JOU}$ & 92.0 & $\operatorname{Logit}(\hat{\pi})=-3.329+0.038 \mathrm{yr}$ & 1.04 & 0.484 \\
\hline & IRB & 67.0 & $\operatorname{Logit}(\hat{\pi})=-2.116-0.020 \mathrm{yr}$ & 0.98 & 0.696 \\
\hline \multirow[t]{4}{*}{ Semi-arid } & MAF & 41.0 & $\operatorname{Logit}(\hat{\pi})=-1.198-0.040 \mathrm{yr}$ & 0.96 & $0.090 *$ \\
\hline & QAI & 43.0 & $\operatorname{Logit}(\hat{\pi})=-0.370-0.163 \mathrm{yr}$ & 0.85 & $0.024 * *$ \\
\hline & $\mathrm{AMM}$ & 58.8 & $\operatorname{Logit}(\hat{\pi})=-0.934-0.039 \mathrm{yr}$ & 0.96 & $0.018 * *$ \\
\hline & ZAR & 31.3 & $\operatorname{Logit}(\hat{\pi})=-1.817-0.038 \mathrm{yr}$ & 0.96 & 0.479 \\
\hline \multirow[t]{3}{*}{ Arid } & AZR & 27.5 & $\operatorname{Logit}(\hat{\pi})=-1.457-0.062 \mathrm{yr}$ & 0.94 & 0.254 \\
\hline & $\mathrm{H} 4$ & 27.2 & $\operatorname{Logit}(\hat{\pi})=-3.261+0.024 \mathrm{yr}$ & 1.02 & 0.281 \\
\hline & H5 & 25.0 & $\operatorname{Logit}(\hat{\pi})=-1.796-0.017 \mathrm{yr}$ & 0.98 & 0.444 \\
\hline
\end{tabular}

*: Significant at $\alpha \leq 0.1$; **: Significant at $\alpha \leq 0.05$; ***: Significant at $\alpha \leq 0.01$
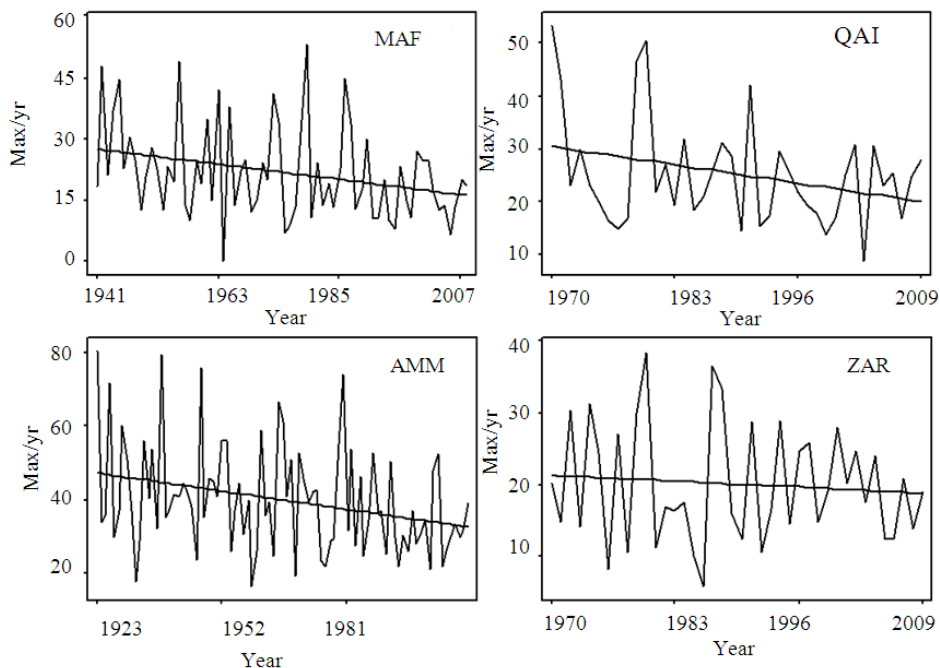

Fig. 2: Linear trend models of maximum rainfall/year for semi-arid stations
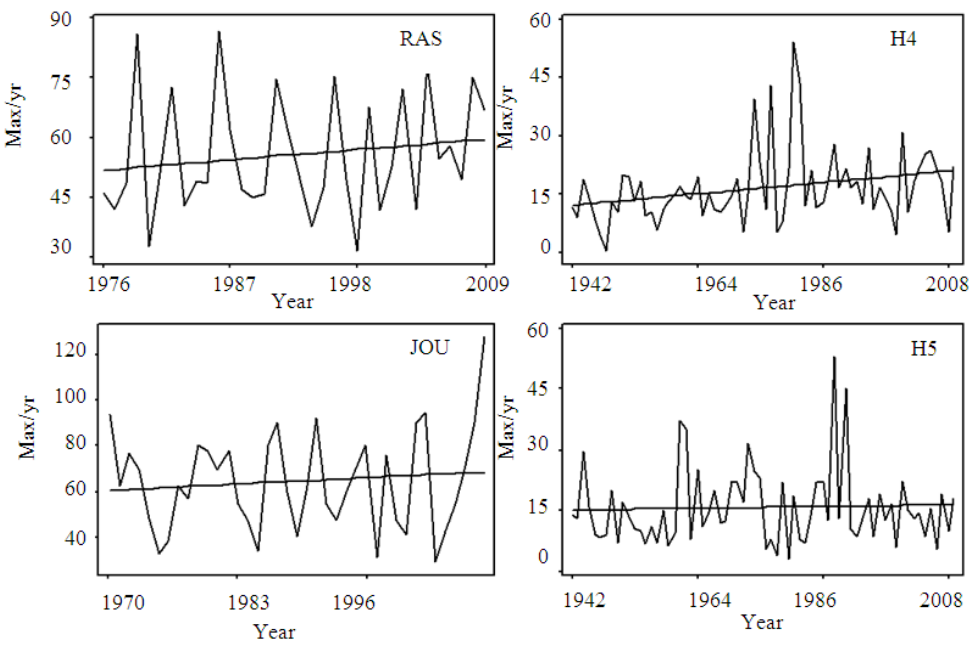

Fig. 3: Linear trend models of maximum rainfall/year for selected non-semi-arid stations. Sub-Humid (Left); Arid (Right) 
Am. J. Environ. Sci., 7 (4): 331-337, 2011
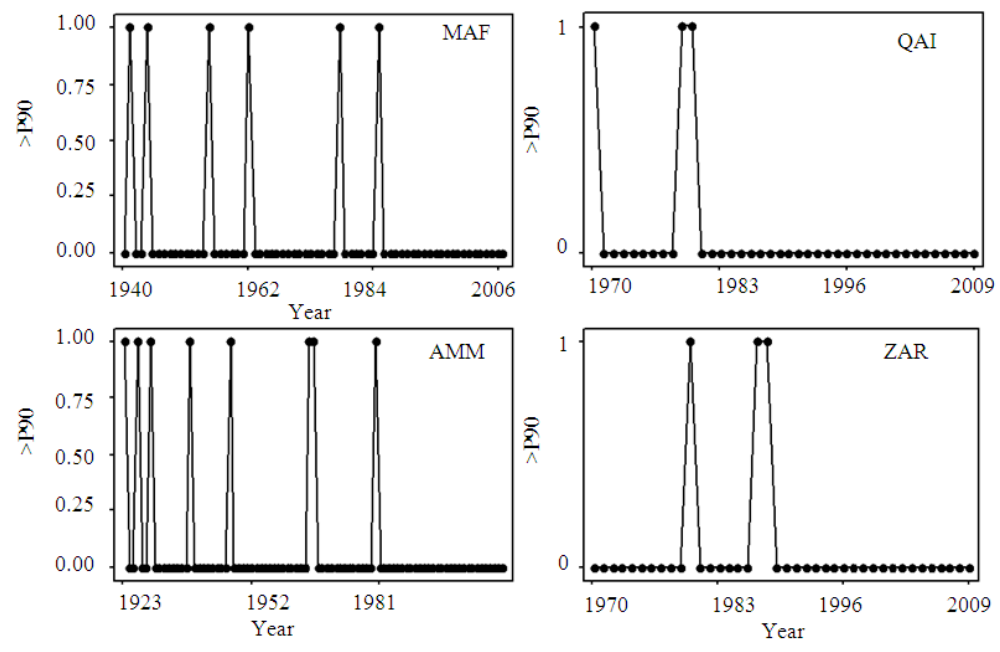

Fig. 4: Frequency of Maximum rainfall for rainfall events above P90 for semi-arid stations

\section{DISCUSSION}

Jordan's climate is highly variable as it represents a transition from the Mediterranean climate represented in this study by the northwestern stations (e.g., IRB, RAS and JOU) to arid climate represented by the eastern stations (e.g., AZR, H5 and H4). Semi arid zone which lies on the margin between subhumid and arid zones is represented by stations (MAF, ZAR, QAI and AMM). The results of this study show spatial and temporal trends in rainfall data in transitional climatic region. Spatially, there is a decreasing trend of rainfall from the northwest towards the east and south east. Mean annual rainfall and mean maximum daily rainfall are increasing but statistically not significant in two stations (RAS and JOU) in the subhumid zone and this is consistent with the findings with similar nearby subhumid regions such as central western parts of the Jordan river (Alpert et al., 2002; Wettenberg et al., 2007; Yusef et al., 2009). Mean annual rainfall in the semi-arid zone shows a general nonsignificant decreasing trend and this agrees with some earlier studies which reported nonsignificant decrease in mean daily and monthly rainfall (Freiwan and Kadioglu, 2008a; 2008b; Ghanem, 2011). But, this study shows that maximum daily rainfall is a more sensitive rainfall index to variability than other rainfall indices, especially in the semi arid regions. Three rainfall stations out of four in this study, namely AMM, QAI and MAF stations (Fig. 1) in the semi-arid zone show significant downward trend (Table). In addition, only semi-arid zone shows significant decreasing trend in the heavy daily rainfall with intensities above $90^{\text {th }}$ percentile among the maximum values Table 3 . This confirms that semi-arid environments are fragile and more sensitive to climatic changes than arid and humid to subhumid regions (Batisani and Yarnal, 2010). Redistribution of daily rainfall intensities due to climate change is of most interest particularly in the semi-arid subtropical regions for purposes of water management, water engineering structures design, soil erosion and flash floods impacts and agricultural practices (Alpert et al., 2004, Alam et al., 2011). The results of this study suggest that the semi arid zone in Jordan is more vulnerable to climate change. Therefore, more serious actions to mitigate and adapt to these changes should be given a priority in the semi arid zone.

\section{CONCLUSION}

As a contribution to understand trends in rainfall variability in a marginal desert environment and to put this understanding in a context of climate change, this study comes to explore trends in maximum daily rainfall in Jordan. The results show that semi- arid rainfall stations are more sensitive to climate change and show significant statistically downward trend in mean maximum daily rainfall. Also this significant trend has been confirmed with rainfall events above $90^{\text {th }}$ percentile among the maximum. However, subhumid and arid stations show no significant trend. Redistribution of daily rainfall intensities is of utmost importance for water resources management in semiarid climates. 


\section{ACKNOWLEDGEMENT}

The rainfall data used in this study were purchased from JMD through funding from the Deanship of Scientific Research at Yarmouk University (project number 23/2010)

\section{REFERENCES}

Agresti, A., 1996. An Introduction to Categorical Data Analysis. 1st Edn., Wiley and Sons. Int., Hoboken, New Jersy, ISBN: 10: 0471113387, pp: 290.

Alam, M.M., M.E. Bin Toriman, C. Siwar and B. Talib, 2011. Rainfall Variation and changing pattern of agricultural cycle. Am. J. Environ. Sci., 7: 82-89. DOI: 10.3844/ajessp.2011.82.89

Alpert, P., I. Ostensky, B. Ziv and H. Shafir, 2004. Semi-objective classification for daily synoptic systems: application to the eastern Mediterranean climate change. Int. J. Climatol., 24: 1001-1011. DOI: 10.1002/joc.1036

Alpert, P., T. Beg-gai, A. Baharad, Y. Benjamini and D. Yekutieli et al., 2002. The paradoxical increase of Mediterranean extreme daily rainfall in spite of decrease in total values. Geophysical Res. Lett. 29: $\mathrm{x} 1-\mathrm{x} 4$.

Al-Qudah, K.A., 2011. Floods as water resource and as a hazard in arid regions: A case study in Southern Jordan. Jordan J. Civil Eng., 5:148-160.

Batisani, N. and B. Yarnal, 2010. Rainfall variability and trends in semi-arid Botswana: Implications for climate change adaptation policy. Applied Geography, 30: 483-489. DOI: 10.1016/j.apgeog.2009.10.007

Black, E., 2009. The impact of climate change on daily precipitation statistics in Jordan and Israel. Atmos. Sci. Lett., 10: 192-200. DOI: 10.1002/asl.233

Easterling, D.R, J.L. Evans, P. Ya Groisman, T.R. Karl and K.E. Kunkel et al., 2011. Observed variability and trends in extreme climate events: A brief review. Bull. Am. Meteorol. Sci., 81: 417-425.

Easterling, D.R., G.A. Meehl, C. Parmesan, S.A. Chagnon and T.R. Karl et al., 2000. Climate extremes: observations, modeling and impacts. Science, 289: 2068-2074. DOI: 10.1126/science.289.5487.2068

Freiwan, M. and M. Kadioglu, 2008a. Climate variability in Jordan. Int. J. Climatol., 28: 69-89. DOI: $10.1002 /$ joc. 1512

Freiwan, M. and M. Kadioglu, 2008b. Spatial and temporal analysis of climatological data in Jordan. Int. J. Climatol., 28: 521-535. DOI: $10.1002 /$ joc. 1562
Ghanem, A.A., 2011. Climatology of the areal precipitation in Amman/Jordan. Int. J. Climatol., 31: 1328-1333. DOI: $10.1002 /$ joc. 2160

Groisman, P., R.W. Knight, D.R. Easterling, T.R. Karl and G.C. Hegerl et al., 2005.Trends in Intense Precipitation in the Climate Record. J. Climate., 18: 1326-1350.

Kadioglu, M., Y. Tulunay and. Y. Borhan, 1999. Variability of Turkish precipitation compared to El Niño events. Geophysical Res. Lett., 26: 15971600. DOI: 10.1029/1999GL900305

Karl, T.R. and R.W. Knight, 1995. Secular trends of precipitation amount, frequency, and intensity in the United States. Bull. Am. Met. Soc., 79: 231241.

Kostopoulou, E. and P.D. Jones, 2005. Assessment of climate extremes In the Eastern Mediterranean. Meteorol Atmos. Phys., 89: 69-85. DOI: 10.1007/s00703-005-0122-2

Oikonomon, C., H.A. Flocas, D.N. Asimakopoulos and C. Giannakopoulos, 2008. Future changes in the occurrence of extreme precipitation events in eastern Mediterranean. Global NEST J., 10: 255262.

Onoz, B. and M. Bayazit, 2003. The power of statistical tests for trend detection. Turkish J. Eng. Env. Sci., 27: 247-251.

Smadi, M.M. and A. Zghoul, 2006. A sudden change in rainfall characteristics in Amman, Jordan during the mid 1950s. Am. J. Environ. Sci., 2: 84-91. DOI: $10.3844 /$ ajessp.2006.84.91

Trenberth, K. E. 2008. The Impact of Climate Change and Variability on Heavy Precipitation, Floods, and Droughts. Encyclopedia of Hydrological Sciences. DOI: 10.1002/0470848944.hsa211

Trenberth, K.E., 2011. Changes in precipitation with climate change. Clim. Res., 47: 123-138. DOI: $10.3354 / \mathrm{cr} 00953$

Wettenberg, L., H. Kutiel, N. Greenbaum and M. Inbar, 2007. Short-term changes in the magnitude, frequency and temporal distribution of floods in the Eastern Mediterranean region during the last 45 years-Nahal Oren, Mt. Carmel, Israel. Geomorphology, 84: 181-191. DOI: 10.1016/J.GEOMORPH.2006.01.046

Yusef, Y., H. Saaroni and P. Alpert, 2009. Trends in Daily Rainfall Intensity Over Israel 1950/1-2003/4. Open Atmospheric Sci. J., 3: 196-203. 